\title{
DEL ARTE DE GUÍAR: APUNTES SOBRE LAS INTRODUCCIONES DE LAS OBRAS COMPLETAS DE F. NIETZSCHE
}

About the Art of Guiding: Notes on the Introductions of the Complete Works of F. Nietzsche

\author{
José Emilio Esteban Enguita \\ Universidad Autónoma de Madrid
}

\begin{abstract}
RESUMEN: El propósito de este artículo es analizar las introducciones escritas por el profesor Diego Sánchez Meca para la edición de las Obras completas de F. Nietzsche en lengua castellana. Como resultado de este análisis, señalamos tres logros principales: primero, la división de la evolución del pensamiento de Nietzsche en dos etapas y no en tres; segundo, la pertinente valoración de sus escritos filológicos y del problema de la filología a través de toda su obra, y, tercero, la articulación de los conceptos fundamentales de su última filosofía a partir de las propuestas de Así habló Zaratustra.

Palabras clave: Introducciones - Diego Sánchez Meca - Obras completas - Nietzsche
\end{abstract}

Aвstract: This paper aims to analyze the introductions written by Professor Diego Sánchez Meca for the edition of the Complete Works of F. Nietzsche in Spanish. As a result of this analysis, we point out three main achievements: first, the division of the evolution of Nietzsche's thought in two stages and not in three; second, the pertinent appreciation of his philological writings and the problem of philology throughout his work, and, thirdly, the articulation of the fundamental concepts of his latest philosophy from the approaches of Thus spoke Zarathustra.

Keywords: Introductions - Diego Sánchez Meca - Complete Works - Nietzsche

Existen modos distintos de introducir una obra de filosofía o las obras completas de un filósofo que nos muestran, como en el caso que nos ocupa, el curso — quizá sería más adecuado hablar de «itinerarios»— por el que ha discurrido su pensamiento. Las introducciones que abren el camino de cada uno de los cuatro volúmenes que componen la edición de las Obras completas de F. Nietzsche ${ }^{1}$, cuyo autor es el profesor Diego Sánchez Meca, responsable también de la edición mencionada, pueden valer perfectamente, si se las toma en su conjunto, como una pertinente monografía introductoria en castellano del pensamiento de Nietzsche. En calidad de tal, responde a una modalidad introductoria cuyo propósito último no es tanto exponer de forma resumida y compacta las ideas principales del autor o los referentes contextuales y biográficos más relevantes, o ambas cosas, algo

1. F. Nietzsche, Obras completas, ed. de D. Sánchez Meca, Madrid: Tecnos, vol. I (Escritos de juventud), 2011; vol. II (Escritos filológicos), 2013; vol. III (Escritos de madurez I), 2014; y vol. IV (Escritos de madurez II y Complementos a la edición), 2016. 
que, por otro lado, también se nos ofrece, sino poner a disposición del lector una especie de guía de lectura, una orientación general a partir de la cual cada uno pueda adentrarse y explorar cualquiera de las zonas del pensamiento de Nietzsche ${ }^{2}$. Como si de un guía se tratara, Sánchez Meca nos conduce con sus introducciones a un punto elevado desde el que puede captarse con la mirada la totalidad del vasto territorio de la filosofía del pensador alemán, incitando al conducido de esta manera a que, ya por su cuenta, se adentre en los distintos lugares que forman ese dominio filosófico y los conozca en detalle por él mismo y ya no tanto por la mano de otro. Aunque quizá no siempre se consiga, sin embargo, somos de la opinión que es preponderante en estas introducciones la finalidad de ejercer orientación, pero no tutela, y, sobre todo, de despertar en el lector el interés no de la lectura de otros libros sobre Nietzsche, sino de la obra del filósofo alemán. A nuestro juicio, este y no otro ha de ser el telos principal de una monografía introductoria, que no avanzada, pues estas últimas requieren, para ser provechosas, un cierto conocimiento previo del autor del que tratan, y no así, en cambio, las primeras.

Si consideramos estas introducciones como la primera versión de una monografía en el sentido indicado anteriormente, esta podría ser situada, en una primera y aproximada localización, entre dos puntos o polos representados por dos célebres textos sobre Nietzsche que han marcado grosso modo las tendencias principales de las introducciones generales acerca del filósofo alemán desde los años sesenta del siglo pasado. Nos referimos, en un extremo del espectro, al libro de E. Fink Nietzsches Philosophie $e^{3}$; en el otro, al de M. Montinari Che Cosa ha detto Nietzsche $e^{4}$. Ambos han de entenderse como referentes ideal-típicos que nos pueden servir para clasificar las distintas monografías introductorias en función de su vecindad con uno o con otro, y para señalar otra clase de introducciones - como esta de Sánchez Meca- que, no escorándose hacia ninguno de los extremos, pretende eludir, sobre todo, los defectos de ambos polos y asimilar de forma adecuada sus virtudes. Una interpretación como la de E. Fink nos ofrece una perspectiva unilateralmente metafísica e inspirada en gran medida por la exégesis heideggeriana de Nietzsche, simplificando de este modo la complejidad de un pensamiento afectado por una multiplicidad de factores e influencias histórico-culturales que sobrepasan con mucho el estrecho marco de un «Nietzsche metafísico» o un Nietzsche cuya obra se explica reduciéndola a un solo motivo, a saber: su posición crítica respecto de la metafísica o de la tradición filosófica. La de M. Montinari, por el contrario, utiliza de forma ejemplar el método «histórico-crítico» y el cuidado filológico característico de la Nietzsche Forschung ${ }^{5}$,

2. En este específico sentido, y por encima de las diferencias, se puede establecer la proximidad entre estas introducciones y el libro de Enrique López Castellón Leyendo a Nietzsche, Madrid: UAM, 2008.

3. E. Fink, Nietzsches Philosophie, Stuttgart: W. Kohlhammer, 1960. Edición en castellano: La filosofía de Nietzsche, trad. de A. Sánchez Pascual, Madrid: Alianza, 1966.

4. M. Montinari, Che cosa ha detto Nietzsche, ed. de G. Campioni, Milano: Adelphi, 1999. Este libro aparece por primera vez en 1975, publicado por la editorial romana Ubaldini, dentro de la colección "Che cosa hanno 'veramente' detto». Edición en castellano: Lo que dijo Nietzsche, trad. de E. Lynch, Barcelona: Salamandra, 2003.

5. Sobre la Nietzsche Forschung y su impulso novedoso en la orientación de los estudios nietzscheanos, cf., por ejemplo, H. Frey, La sabiduría de Nietzsche. Hacia un nuevo arte de vivir, Puebla: Universidad de las Américas Puebla/Miguel Ángel Porrúa, 2007, pp. 33-42. 
atendiendo cuidadosamente al marco histórico-biográfico en el que se desenvuelve el pensamiento del filósofo alemán. Nos proporciona toda una gama rica en matices (relaciones personales, lecturas realizadas, debates culturales, acontecimientos sociales y políticos, etc.) sin los que difícilmente podríamos dar cuenta de la multiplicidad y riqueza de los motivos e influencias que van tomando cuerpo en la evolución de su filosofía. Sin embargo, la interpretación que pone en nuestras manos M. Montinari rebaja en cierto sentido la profundidad de la reflexión filosófica de Nietzsche, pues simplifica en ocasiones las tramas conceptuales que va tejiendo y destejiendo a lo largo de su obra. La reducción histórico-crítica del pensamiento de alguien como Nietzsche, cuya vocación fue eminentemente la de un filósofo, llevada a cabo en exceso, tiene como consecuencia indeseable la trivialización de los problemas filosóficos que palpitan intensamente en todos y cada uno de sus libros. La pretensión de eludir ambos peligros, encontrando la medida adecuada que permita una fuerte ligadura entre las cuestiones filosóficas de la obra del filósofo alemán, que exigen un ejercicio de interpretación sistemática de contenidos derivado de una lectura marcada por un tempo lento, y su contextualización histórico-crítica, sin la que sus elaboraciones filosóficas flotarían en una especie de vacío carente de orientación alguna —salvo, quizá, la impuesta arbitrariamente por el intérprete de turno- o, peor aún, en la inane doxografía que todo lo convierte en glosa o comentario, es algo que caracteriza los textos introductorios del profesor Sánchez Meca, razón por la cual pueden considerarse como pertenecientes a un tercer tipo distinto y, a nuestro juicio, más productivo, que los representados por E. Fink o M. Montinari.

Muchos lugares comunes siguen vigentes en el caso de la recepción del pensamiento de Nietzsche, y no solo entre los que lo conocen poco o simplemente lo desconocen, sino también entre algunos de aquellos que han trabajado su obra. Las turbulencias que ha sufrido la transmisión de su legado durante la mayor parte del siglo pasado y su condición de outsider para muchos de los académicos pertenecientes al campo de la filosofía de distintos países, especialmente los de su país natal, "Alemania», haciendo bueno el dicho de que nadie es profeta en su tierra, han contribuido, sin duda, a la creación de esta tópica distorsionadora que todavía, a pesar de la cantidad de rigurosos estudios que deberían haber funcionado como disolvente efectivo de groseras adulteraciones de su filosofía, persiste en muchos sectores culturales y en algunos ámbitos universitarios. Entre estos tópicos, mantiene su fuerza el que considera que la evolución de su pensamiento pasa por tres etapas, denominadas «de juventud», «intermedia» $\mathrm{y}$ «de madurez». Si atendemos con cuidado al desenvolvimiento de su filosofía, tal periodización es difícilmente sostenible: debería causar perplejidad hablar de un intermezzo que parece venir del cielo y que no obedece a la propuesta de una «lógica interna» en el desarrollo de sus posiciones, o de una fase de madurez que, a todas luces y debido a su desplome psíquico, quedaba abruptamente finiquitada a comienzos de 1889 y, por consiguiente, incompleta. Tanto la manera en la que se dividen y distribuyen en cuatro volúmenes estas Obras completas, como lo que se indica de forma meridiana en sus introducciones, muestra inequívocamente la pertinencia de establecer dos épocas o etapas en el despliegue de la meditación filosófica de Nietzsche: la de «juventud» y la de «madurez». Hay que resaltar, respecto a la primera, la importancia que se otorga a los textos de los años de formación que se remontan hasta 1862, con el 
escrito Fatum e historia, con la intención de mostrar el largo y relevante proceso de maduración que desembocaría en El nacimiento de la tragedia y la necesidad de prestar la debida atención a esa larga fase de gestación ${ }^{6}$. Si hablamos del llamado "periodo de madurez», tenemos que hacer hincapié en las bondades de esta interpretación, pues, de cara a una mejor comprensión de la evolución del pensamiento del filósofo alemán, elimina el incomprensible periodo intermedio calificado como «ilustrado» ${ }^{7}$ y establece un periodo de madurez —entendido como el punto en el que Nietzsche comienza a lograr una decisiva autonomía en su proyecto filosófico - subdividido a su vez en una fase temprana que abarca el intervalo de 1876 a 1882 y en una tardía que, comenzando en 1883 con Así habló Zaratustra, alcanza hasta el final de su vida lúcida y cuyo contenido principal es esa «filosofía del porvenir» que quedaría inconclusa. El extraño Nietzsche «ilustrado» $\mathrm{y}$ «positivista» que parece surgir repentinamente de la nada y que a partir del Zaratustra es misteriosamente tragado por las tinieblas, es presentado por Sánchez Meca como el caminante que toma la senda de la crítica genealógica de la cultura y de sus magnos productos, de la modernidad en su conjunto, utilizando la ciencia como herramienta crítica (de ahí, lo de «positivista») y radicalizando la crítica ilustrada, atacando no solamente los viejos prejuicios, sino también cuestionando los nuevos en los que se asentaba el espíritu (racional) ilustrado (de ahí, lo de «ilustrado»). El Nietzsche «intermedio» es, en realidad, un «ultrapositivista» y un «ultrailustrado» en el específico sentido de que precisa del arsenal crítico que le brinda la ciencia moderna y el movimiento ilustrado (al menos parte de él) para desenmascarar y destruir los viejos ideales y los nuevos dioses que pretendían reemplazarlos, y poder construir, devenido «espíritu libre», una nueva interpretación de la existencia.

En el momento en que se establecen dos etapas o periodos a la hora de exponer el desenvolvimiento del pensamiento de un filósofo, se impone de manera forzosa tratar la relación entre ambos periodos, emergiendo la cuestión de si hay que considerar una visión de conjunto en que predomine la continuidad u otra en la que tome un peso mayor la idea de ruptura entre ambas etapas. El primer epígrafe de la introducción al tercer volumen de las Obras completas formula con toda claridad el problema: «De los años de juventud a La gaya ciencia: cruptura o continuidad? $»^{8}$. Hay que decir, por adelantando, que en este punto existen diferencias entre los estudiosos de la obra de Nietzsche. También es conveniente plantear la cuestión no en términos maximalistas y en cierta medida draconianos, en términos de "o esto o lo otro", sino conducirla a una zona de tonos grises en la que hay que evaluar qué cambia y en qué sentido lo hace, así como lo que permanece y, por ello, garantiza en algunos o en muchos aspectos la continuidad. La posición hermenéutica del profesor Sánchez Meca se inclina por la asunción de una hipótesis fuerte en favor de la continuidad: por un lado, la crítica genealógica que comienza con Humano, demasiado humano, prosigue con Aurora y La gaya ciencia y logra su plena madurez en la genealogía de la mo-

6. Cf. D. Sánchez Meca, «Introducción», en Obras completas, vol. I, Madrid: Tecnos, 2011, pp. 13-23.

7. Cf. D. Sánchez Meca, «Introducción», Obras completas, vol. III, Madrid: Tecnos, 2014, pp. 19-20.

8. Ibid., p. 13. 
ral, «no es sino el desarrollo coherente y por tanto maduración, de la ensayada y practicada en sus escritos de juventud. En ellos, el uso crítico de determinado método de análisis y explicación conduce ahora a una filosofía que se autocomprende como crítica de la cultura ${ }^{9}$; por otro, los grandes temas estructurados de su pensamiento maduro, tal y como se encuentran en Así habló Zaratustra, se conciben como «un desarrollo metafórico-conceptual de una sabiduría trágica que ya había sido inicialmente intuida y esbozada en El nacimiento de la tragedia y que constituye el núcleo más íntimo y determinante de todo el pensamiento nietzscheano» ${ }^{10}$. Que 1876 o Humano, demasiado bumano - el "monumento a una crisis» ${ }^{11}$, como nos dice Nietzsche en Ecce Homo- no ha de entenderse como una «súbita conversión» a una nueva filosofía, sino que la fractura o el cambio respecto a lo anterior se va gestando desde 1873, añadiéndose elementos críticos puntuales que darían paso a la perspectiva genealógica, supone, a nuestro juicio, no tanto una maduración de la crítica cultural sustentada en la metafísica de artista, sino una relevante transformación de dicha crítica que asume la forma genealógica, la cual solo puede abrirse paso desde una «filosofía histórica» que se contrapone a toda «filosofía metafísica», incluida en esta categoría la que había mantenido en la etapa anterior ${ }^{12}$. En el otro respecto, la metafísica de artista de su época de juventud y la «filosofía del porvenir» de su madurez como planteamientos de la sabiduría trágica, cuyo problema fundamental — uno y el mismo- es la pregunta por el sentido de lo dionisíaco, conllevan diferencias suficientes y relevantes para convertir en discutible, a nuestro juicio, la idea de una evolución «natural» del pensamiento de Nietzsche en virtud de la cual su filosofía a partir de Así habló Zaratustra se interpreta como la realización de las rationes seminales (intuiciones y esbozos) presentes en su primera obra publicada y efectivas y determinantes para la evolución de su pensamiento. En cualquier caso, pensamos que este problema hermenéutico es conveniente plantearlo en términos de matices y de gradaciones que modulen y precisen lo que cambia y lo que permanece, que así se pueden alcanzar puntos de vista convergentes por debajo o por encima de las diferencias, y que, lo que es lo más decisivo, bien se incline uno por la «continuidad» o por la «ruptura», existe un único campo de fuerzas que otorga, independientemente de sus configuraciones, coherencia a la evolución de su filosofía. Apelamos a la célebre distinción de I. Berlin para precisar esta consideración: Nietzsche es un pensador-erizo, no un pensador-zorro ${ }^{13}$, y por eso es un filósofo de un solo y determinante problema que, eso sí, va recibiendo planteamientos diferentes en el desarrollo de su pensamiento.

9. Ibid., p. 15

10. D. Sánchez Meca, «Introducción», en Obras completas, vol. IV, Madrid: Tecnos, 2016, p. 18.

11. EH, KSA VI 322.

12. MA (I), KSA II 23. Por esta razón, la crítica genealógica de nuestros prejuicios morales comienza, stricto sensu, a partir de Humano, demasiado humano, como nos dice el propio Nietzsche en la Introducción a La genealogía de la moral (cf. KSA V 248); y, por eso, Nietzsche dice de Zaratustra: «Hubo un tiempo en que también Zaratustra proyectó su ilusión más allá del hombre, igual que todos los trasmundanos. Por entonces el mundo me parecía la obra de un Dios sufriente y atormentado» (KSA IV 35. Trad. esp. de A. Martín Navarro, Obras completas, vol. IV, cit., p. 86).

13. I. Berlin, Pensadores rusos, trad. J. J. Utrilla, México D. F.: FCE, 1980, pp. 69-70. 
No cabe ignorar el mérito que supone la inclusión de los textos filológicos de Nietzsche en estas Obras completas y la pertinente introducción que se hace a los mismos, no solo por el hecho señalado por Sánchez Meca de su injusto olvido por parte de filólogos y filósofos, sino por la centralidad que tiene la reflexión en torno al problema de la filología en su filosofía de juventud y en sus evidentes derivaciones posteriores ${ }^{14}$. De hecho, la cuestión de la ciencia, ese «problema con cuernos» $»^{15}$ que afronta por vez primera en El nacimiento de la tragedia y que constituye una de las claves determinantes de toda su filosofía, toma su primera forma relevante como una crítica, llevada a cabo desde un incuestionable horizonte filosófico, de la ciencia filológica y de la profesión del filólogo. Lo que no comprendía o ya no aceptaba por una mirada miope y por una asunción acrítica y dogmática de determinados principios metodológicos la mayoría dominante de la comunidad filológica de su tiempo, era la condición híbrida y compleja de la filología, un saber que reunía en su seno fuerzas en pugna tan dispares como la filosofía, la ciencia y el arte. No hace falta acudir a El nacimiento de la tragedia para conocer la concepción integral y compleja de la filología por parte de Nietzsche, especialmente por el aliento fundamentalmente filosófico y no tanto filológico de esa polémica obra: en textos como Homero y la filología clásica (1869) y Enciclopedia de la Filología clásica: Cómo se llega a ser filólogo (1870-1871), escritos eminentemente filológicos, se encuentra la consideración reflexiva de un filólogo de profesión sobre las condiciones de posibilidad de la ciencia filológica. La filología es una ciencia, pero también es algo más que una ciencia: no se trata de ignorar los métodos empíricopositivos necesarios para todo saber que merezca el nombre de ciencia, sino de vincularlos a un marco filosófico y a una finalidad «cultural» que deben poder ser integrados por una genuina filología. Dicho con otras palabras: la filología es un centauro porque ha de integrar, formando un organismo viable, la investigación característica de la ciencia y la interpretación propia de la filosofía. La filología, como ciencia o saber positivo, no solo es respetable, también es necesaria y completamente legítima en la jurisdicción que le corresponde. Su sentido, sin embargo, no proviene de su actividad como ciencia, sino de su dirección por parte de la filosofía tanto desde un punto de vista teorético como práctico. Como ciencia de la Antigüedad, la filología es un instrumento al servicio de tres propósitos fundamentales: primero, la reconstrucción de una totalidad que ha de valer como un modelo (Vorbild) surgido de una interpretación global del mundo antiguo capaz de integrar los resultados del proceso de especialización que ya afectaba también a la Althertumswissenschaft en su época; segundo, la implantación de un programa de formación (Bildung), heredero y crítico del clasicismo, que permita el florecimiento de una genuina individualidad; por último, la crítica cultural a la modernidad —destacándose en ella los durísimos ataques a la Alemania del Segundo Reich-, afectada en todos sus ámbitos fundamentales por procesos disolventes y de fragmentación, mediante su contraposición con una imagen de la cultura trágica griega garante de la unidad de todas las manifestaciones vitales de ese pueblo ${ }^{16}$.

14. Cf. D. Sánchez Meca, «Introducción», en Obras completas, vol. II, Madrid: Tecnos, 2013, pp. 15-21.

15. GT, KSA I 13.

16. Sobre estos tres cometidos de la filología, cf. D. Sánchez Meca, «Introducción», en Obras completas, vol. II, cit., pp. 22-26. 
Esta idea de la filología, tan heterodoxa que le valió su certificado de defunción por parte de los más eximios representantes de la comunidad filológica, opera en el pensamiento del joven Nietzsche no solo como una autorreflexión necesaria de la ciencia y de la práctica científica, sino también como la vinculación de su filosofía con la ciencia, que en este momento significa principalmente filología, un nexo sin el cual no nos parece posible comprender de forma adecuada la doble dimensión que caracteriza el primer periodo del pensador alemán: por un lado, su metafísica de artista; por otro, su crítica cultural al mundo moderno y su propuesta de superación de un tiempo amenazado por la barbarie tal y como son expuestas en el ciclo formado por las cuatro Intempestivas. Que estas son las dos fuerzas predominantes que organizan el campo de su filosofía de juventud y que la filología y todo lo que para Nietzsche implica está entrelazada con ellas de tal modo que filosofía, ciencia y política (cultural) forman un todo cuyas partes son inseparables, constituyen las dos instancias determinantes que configuran el horizonte de sentido de aquella "primera» filosofía. La metafísica de artista comenzará a erosionarse a partir de 1873, aunque seguirá estando vigente, al menos como «metafísica», hasta su abandono por una «filosofía histórica» que inicia el camino con Humano, demasiado bumano. La suerte de la filología, como muy bien señala Sánchez Meca, matizando su interpretación en favor de la continuidad, cambia, aunque no pierde su relevancia dentro del pensamiento de Nietzsche: de una ciencia que se justifica en la medida en que sirve de medio fundamental tanto para la crítica de la cultura moderna como para la cimentación de una verdadera Bildung, primando en ella una concepción mítica de raíces estéticas sobre la comprensión científica, a un arte de leer bien y con la demora metódica necesaria un texto, con el propósito crítico de descubrir los códigos cifrados que revelan su sentido profundo, sin «intuiciones metafísicas» $\mathrm{y}$ «verdades grandilocuentes» que la orienten. Ahora, la filología, en tanto que análisis crítico de la tradición, se convierte en capital indispensable de la interpretación genealógica ${ }^{17}$.

No hay, pues, intermezzo alguno entre juventud y madurez. Dejando en suspenso la cuestión de la continuidad o de la ruptura entre los dos periodos, el paso de una etapa a otra, en cualquier caso, viene marcado por la entrada de Nietzsche en una especie de mayoría de edad filosófica caracterizada por la conformación progresiva de la perspectiva genealógica como método filosófico de interpretación. En este sentido, es afortunada la expresión empleada por Sánchez Meca para caracterizar esta conquista de la autonomía: «revolución copernicana axiológica» ${ }^{18}$. Comienza a crearse el camino hacia la transvaloración de todos los valores, hacia la superación, entonces, de lo que dentro de muy poco llamaría «nihilismo» y de la hegemonía de la decadencia: un inicio marcado por la negatividad de una crítica que pretende socavar los fundamentos de las egregias manifestaciones de la civilización occidental, de su arte, de su moral, de su filosofía y de cierta «atmósfera religiosa» (cristiana) que todo lo impregna. El hilo dorado de Ariadna que conduce a Nietzsche por el laberinto de la crítica y le proporciona la precisa orientación que necesita es el dominio de la moral, la moral como problema, una cuestión que para el filósofo alemán nunca se había planteado hasta ahora

17. Cf. ibid., pp. 40-42.

18. Cf. D. Sánchez Meca, «Introducción», en Obras completas, vol. III, cit., p. 25. 
porque la hegemonía incuestionable de un sistema de valores y de un modo de valorar que acabaría identificando con el nombre de «ideal ascético» lo había impedido. La crítica de la cultura va de la mano del desenmascaramiento de la moral como su fenómeno más determinante. En este sentido, el caso de la filosofía es paradigmático: que la moral haya sido su Circe durante su historia y que la crítica emancipadora de la filosofía moderna desaparezca justamente cuando pisa el terreno de la moral, lo dice todo. La autonomía del filósofo se torna en su contrario o, mejor dicho, se descubre su irresistible inclinación a la impostura. No hay mejor ejemplo para ilustrar lo anterior, como bien señala Sánchez Meca, que la superlativa tartufería de Kant a juicio del Nietzsche maduro. Combatir en una guerra sin cuartel esa inclinación, o lo que es lo mismo, hacer todo lo posible para aniquilar el dogmatismo de los filósofos, que aflora precisamente cuando de la moral se trata, es tarea crítica y principal de la genealogía ${ }^{19}$. También la exploración y su consiguiente desmistificación, utilizando técnicas de excavación, del subsuelo credencial, tan poco racional, de categorías fundamentales de la metafísica y de la filosofía moderna como el concepto de «Sujeto», que desde Descartes en adelante opera como fundamento último del conocimiento y de la moral, es misión de la genealogía ${ }^{20}$.

El punto de vista genealógico tiene su foco principal en una suerte de semiótica en virtud de la cual los fenómenos culturales son signos de procesos fisiológicos y de tipos de vida. La clave para el desciframiento de los códigos culturales se encuentra en las fuerzas vitales (dispositivos pulsionales, complejos instintivos, formas volitivas) que aquellos expresan y que, como medios, fomentan, teniendo presente que estas fuerzas se encuentran en pugna con otras en el juego de la conservación y el crecimiento, de la obediencia y del mando, en la lucha en torno a la salud y la enfermedad. Esta perspectiva es la propia de un filósofo que se concibe como "psicólogo» y como «médico», cuya estimativa se determina en función de la relación entre la cultura y la salud, tal y como nos lo plantea Nietzsche, refiriéndose en este caso a la filosofía, en el prólogo incorporado a la segunda edición de $\mathrm{La}$ gaya ciencia. ¿Cuál es la voz de este discurso filosófico, la de un cuerpo enfermo o la de uno sano?, ¿̇contribuye esta filosofía al incremento de las fuerzas vitales o a su mengua?, ¿quién habla aquí, la vida ascendente que persigue en todo momento capitalizar la salud o, sin embargo, la decadencia que busca sin descanso la protección de la enfermedad con todo lo que ella implica?, etc., son las preguntas determinantes que han de hacerse. Su planteamiento caracteriza una forma genealógica de interpretar que tiene en el concepto de cuerpo «el a priori de toda creación y transformación de la cultura», y un marco teórico que «es lo que podríamos llamar una fisiología trascendental basada en la reciprocidad agonal de una lucha de fuerzas que pertenecen al eterno proceso creador y destructor de la physis misma ${ }^{21}$. Estas frases citadas de las introducciones de Sánchez Meca expresan de forma cierta y precisa las condiciones de posibilidad, del método genealógico, exponiendo fielmente el principio en el que se basa la genealogía nietzscheana ${ }^{22}$.

19. Cf. ibid., pp. 34-39.

20. Cf. ibid., pp. 48-52.

21. D. Sánchez Meca, «Introducción», en Obras completas, vol. III, cit., p. 25.

22. Lo que escribe Nietzsche en el mencionado prólogo de La gaya ciencia nos parece un apoyo fuerte a nuestra valoración de la interpretación de la genealogía hecha por Sánchez Meca: cf. FW, KSA III 347-349. 
Que, como se apunta con toda claridad en la introducción al volumen cuarto de estas Obras completas, el Zaratustra ocupa una posición decisiva no solo dentro de toda su producción, sino también, siendo lo que ahora nos interesa, respecto a la evolución de su pensamiento desde aquel libro hasta el final de su vida lúcida, es una consideración fundamental para una comprensión cabal de su filosofía tardía de madurez, si por tal entendemos esos preludios para una filosofía del porvenir que no pudo llevar a su término. La relevancia y singularidad de esta obra, que para Nietzsche significa, por encima de todo, la conversión de su concepto de lo dionisíaco en «acción suprema ${ }^{23}$, reposa a nuestro juicio en el hecho de que representa la respuesta afirmativa a la pregunta que se formulaba en La genealogía de la moral: chay suficiente fuerza, orgullo, seguridad en uno mismo, libertad de la voluntad para que el filósofo sea posible a partir de ahora en la tierra? ${ }^{24}$. Lo que se ha entendido hasta ahora como filósofo y como filosofía no han sido tales, sino servidores y vástagos del sacerdote e ideal ascéticos. Desde esta consideración de las cosas, Zaratustra es el primer filósofo y Así habló Zaratustra es la anticipación de esa verdadera filosofía mentada en la expresión «filosofía del porvenir». Una nueva interpretación (dionisíaca) del mundo, un nuevo concepto de filósofo y una finalidad práctica constituyen los aspectos principales que caracterizan el pensamiento de Nietzsche desde 1883 hasta $1888^{25}$.

La importancia de Así habló Zaratustra radica en que, en esta obra, y solo en esta obra, se encuentran anudados de forma precisa y expresados mediante un decir "poético» los conceptos principales y los grandes temas de lo que ha pasado a la historia de la filosofía como el pensamiento fundamental de Nietzsche. Si los nombramos siguiendo el orden en que aparecen en el relato de las andanzas y discursos de Zaratustra, entonces forman la siguiente secuencia: muerte de Dios (nihilismo consciente de sí), superhombre, voluntad de poder y eterno retorno. Aunque aparece en último lugar, sin embargo, la idea del eterno retorno es el motivo nuclear, como indica Nietzsche y nos repite Sánchez Meca, respecto a la cual se disponen el resto de los conceptos básicos del pensamiento maduro del filósofo alemán. Que el eterno retorno ocupe una posición central no deja de resultar un problema para la interpretación de su pensamiento de madurez, pues tiene todas las características de un «concepto-límite» y, por lo tanto, de implicar un reto para la comprensión de su significado o de la articulación de sus distintos niveles de significación. De hecho, más allá de la asunción de su centralidad, de que su genuina asimilación supone superar la prueba que acredita la incondicional afirmación de la vida y la desbordante salud de una modalidad de la voluntad de poder, y de que su efectiva «incorporación» como doctrina pueda abrir las puertas a la llegada del superhombre, esta idea, como visión y enigma, se mueve en las penumbras y ambigüedades de los oráculos de Delfos. De ahí que el profesor Sánchez Meca, como cualquiera que afronta esta doctrina de Nietzsche, haya de aventurarse en la tarea ímproba de desentrañar su sentido; de ahí que su elucidación de tan obscura visión sea una valiosa pista más — lo que no es poco- para adentrarse en tan abis-

23. EH, KSA VI 343.

24. Cf. GM, KSA V 361.

25. Estos tres aspectos componen los puntos principales del programa de una transvaloración de todos los valores, que puede valer también para caracterizar su pensamiento de madurez: cf. D. Sánchez Meca, «Introducción», en Obras completas, vol. IV, cit., pp. 18-19. 
mal pensamiento. Por todo esto la discrepancia de las interpretaciones al respecto del eterno retorno está servida de antemano, y la nuestra no se libra de este conflicto. Sin embargo, lo más relevante no es, a nuestro juicio, la exégesis que se nos ofrece de tan trascendental visión en estas introducciones, sino la forma como se vincula con sus otras ideas fundamentales y su exposición. Dicho concisamente: el concepto de voluntad de poder, entre otras determinaciones, es una hipótesis hermenéutica, no un principio ontológico o una idea fundamentada en la ciencia, a lo que hay que agregar la clara identificación de las dos modalidades bajo las que se manifiesta dicha voluntad: la afirmativa y la negativa, o, en términos del autor de estas introducciones, la voluntad de poder activa (salud) y la decadente (enfermedad) ${ }^{26}$. Por otro lado, y por encima de cualquiera de las elucubraciones que suscite la palabra Übermensch, de la que, por cierto, tan poco se dice fuera del Zaratustra, quedando en una indeterminación que tanto ha estimulado a la imaginación de los intérpretes, coincidimos con la consideración que se hace de su significado más relevante o, al menos, más claro: el superhombre «no es sino la otra cara de la crítica radical que Nietzsche dirige a la cultura occidental, y la contraimagen del hombre decadente y nihilista ${ }^{27}$.

Esta nueva interpretación del mundo expuesta por Zaratustra es la de un filósofo que se manifiesta como el antípoda del pseudofilósofo dominado por el ideal ascético, y supone un punto de consistencia que va más allá del mero crítico, como psicólogo y médico filosófico, de los ideales de la metafísica, la moral y la religión, de esa fuerza negativa preponderante en Humano, demasiado humano, Aurora y, en menor medida, La gaya ciencia. Ahora, el filósofo, que no deja de ser un crítico y de practicar el método genealógico, adopta una tarea eminentemente propositiva, es decir, constructiva y positiva, que relega a un segundo plano la negación que efectúa la crítica. Se impone con toda claridad aquello a lo que debe servir la crítica y que se afirma con rotundidad en Más allá del bien y del mal: el filósofo como legislador, como el soberano anhelado que graba en nuevas tablas nuevos valores sobre los que se espera que gire un mundo que está por venir ${ }^{28}$. El espíritu libre alcanza su mayoría de edad, cumpliendo así su desarrollo, en la figura del pensador que legisla, fijando así un significado distinto a las poderosas palabras «bueno» $\mathrm{y}$ «malo». Esta nueva legislación es impulsada por una finalidad tan ambiciosa como necesaria ante la percepción de un tiempo caracterizado por la disolución y por el sentimiento de estar viviendo el final de una historia, o lo que es lo mismo, el agotamiento de la civilización occidental, el ocaso de los principios que han educado - domesticado- al género humano. Lo que persigue Zaratustra como filósofo-legislador es superar el nihilismo, una superación que ha de entenderse como autosuperación, y, con ello, la transformación del mundo moderno con la mirada puesta en la posibilidad de una nueva humanidad.

Concluimos: las introducciones del profesor Diego Sánchez Meca a la edición de estas Obras completas pueden utilizarse como una guía solvente para una primera orientación de quien decida adentrarse en la trama compleja del pensamiento

26. Cf. ibid., pp. 34-35.

27. Ibid., p. 53.

28. Ibid., pp. 18-19. 
del filósofo alemán. Si se presentaran unidas en un texto, dispondríamos de una valiosa monografía introductoria. No sería justo, además, si no se dejara aquí constancia del enorme valor que la labor de Sánchez Meca, como editor de las Obras completas y de los Fragmentos póstumos, tiene y va a tener para el conocimiento y la investigación de la filosofía de Nietzsche en lengua castellana. 